\title{
A randomised, placebo-controlled, 24-week, study of low-dose extended-release methylphenidate in adults with attention-deficit/ hyperactivity disorder
}

Michael Rösler · Roland Fischer •

Richard Ammer - Claudia Ose •

Wolfgang Retz $\cdot$ on behalf of the study group

Published online: 31 March 2009

(C) Springer-Verlag 2009

Erratum to: Eur Arch Psychiatry Clin Neurosci (2009) 259:120-129

DOI 10.1007/s00406-008-0845-4

Unfortunately, the name of an author was published with errors. The correct name is C. Jacob instead of C. Jakob.

The online version of the original article can be found under doi:10.1007/s00406-008-0845-4.

M. Rösler $(\bowtie) \cdot$ W. Retz

Neurocenter, Saarland University Hospital,

66421 Homburg/Saar, Germany

e-mail: michael.roesler@uniklinik-saarland.de

R. Fischer - R. Ammer

Medice, Arzneimittel Pütter GmbH \& Co.KG, Iserlohn,

Germany

C. Ose

Institute for Medical Informatics, Biometry and Epidemiology,

University Essen, Essen, Germany 